\title{
SAMBA JUNINO, PATRIMÔNIO CULTURAL DA CIDADE DE SALVADOR: UMA ABORDAGEM HISTÓRICA E CONTEMPORÂNEA
}

\author{
Gustavo José Jaques de Melo \\ Ângela Elisabeth Lühning ${ }^{1}$
}

\begin{abstract}
Resumo: este artigo traz um recorte do texto publicado em 2017 na dissertação, Samba junino: o samba duro e o São João de Salvador, de um dos autores, em uma abordagem histórica e contemporânea da manifestação cultural samba junino, presente em diversos bairros populares da capital baiana. Nele são abordadas suas principais características bem como a influência do contexto social para a sua existência, com argumentos baseados nos textos do jornalista Hamilton Vieira.
\end{abstract}

Palavras-chave: Etnomusicologia. História. Samba junino.

\section{SAMBA JUNINO, CULTURAL PATRIMONY OFTHE CITY OF SALVADOR: A HISTORICAL AND CONTEMPORARY APPROACH}

\begin{abstract}
: this article brings a clipping of the text published in 2017 in the dissertation, Samba Junino: Samba duro e o São João de Salvador, by one of the authors, in a historical and contemporaneous approach to the Samba Junino cultural manifestation present in several popular neighborhoods of the state capital. In it are discussed its main characteristics as well as the influence of the social context for its existence, with arguments based on the texts of the journalist Hamilton Vieira.
\end{abstract}

Key words: Ethnomusicology. History. Samba junino.

\section{Introdução}

Desde os primeiros batuques e arrastões, o samba junino nunca viveu um momento tão promissor, sintetizado no reconhecimento de seu valor cultural atestado pelo título de patrimônio cultural da cidade de

${ }_{1}^{1}$ PPGMUS/UFBA. E-mails: gustavojotamelo@gmail.com/angelaluhning@gmail.com. 
Salvador ${ }^{2}$. Os desafios impostos pelo novo contexto são imensos e requerem ampliar as investigações e cuidados a fim de não tornar um instrumento de proteção de uma manifestação cultural importante para a construção da identidade de uma gente, em algo desastroso, que pode gerar conflitos entre os grupos envolvidos na prática cultural em apreço. Para contribuir para esta reflexão crítica considera-se de extrema importância reconstruir sua história, observando momentos cruciais para o surgimento do samba junino, mesmo que à luz de transformações recentes.

Conforme diversos artigos publicados pelo jornal A Tarde, periódico de grande circulação na Bahia, essa manifestação começa a ser notada, de forma mais ampla, na metade dos anos 80 do século XX, em alguns bairros populares de Salvador, capital da Bahia. Eram grupos de samba que tomavam as ruas desses bairros munidos de instrumentos de percussão e cantando samba de roda, tudo isso com muita alegria e criatividade. Sua formação instrumental contava com o timbal, a marcação e o tamborim como elementos indispensáveis no seu conjunto. Com o tempo, outros instrumentos foram sendo acrescentados como a bateria e os instrumentos harmônicos: violão, cavaquinho, contrabaixo, tudo isso sobre o suporte de um carro de som adaptado ou mesmo um mini trio. Vale ressaltar sua estreita ligação com o samba de caboclo nos terreiros de candomblé, fato relatado inúmeras vezes por seus representantes como principal elemento para sua existência.

Ao som da percussão, grupos de samba tomam as ruas de inúmeros bairros populares da capital baiana com a sua batucada fazendo Samba Junino. Conforme diversos artigos publicados pelo jornal A Tarde, o Samba Junino, que foi notado por esse mesmo meio de comunicação lá pelos idos dos anos 80 em Salvador, é tido como uma forma das populações, que residem em bairros populares da capital, de poder participar do São João com identidade étnica e muita criatividade, recodificando a tradição de origem europeia, com os signos da cultura afro-brasileira, tal qual o samba de roda (MELO, 2017, p. 14).

2 Reconhecimento realizado pela Fundação Gregório de Mattos em maio de 2017. Como parte indispensável nesse processo, foi solicitado um estudo técnico/laudo etnomusicológico, produzido por Ângela Luhning e Gustavo Melo (LUHNING; MELO, 2017). 
Esse ensaio traz um recorte da pesquisa realizada para o curso do mestrado em etnomusicologia iniciada em 2015, cujo tema foi "Samba junino: o samba duro e o São João de Salvador", sob a orientação da professora Ângela Lühning, com o objetivo principal de compreender os processos de criação do samba junino. Esse artigo destaca o contexto histórico baseado, principalmente, em jornais da época e nos relatos de seus interlocutores. É importante destacar que, conforme percebido na pesquisa, há pouca documentação escrita sobre a manifestação em questão, apenas falas associadas ao pagode e samba chula ${ }^{3}$.

\section{Um registro histórico}

Os primeiros registros sobre o samba junino foram encontrados em pequenas notas informativas de jornais, provavelmente de cunho independente. O jornal A Tarde, o mais antigo jornal em circulação na Bahia, por exemplo, menciona pela primeira vez o termo samba junino em 07 de junho de 1985. O texto é apresentado numa coluna intitulada "Roteiro para hoje", na seção caderno 2, divulgando a agenda de shows e espetáculos pela cidade. Até esse momento, o samba junino passa, aparentemente, despercebido aos meios de comunicação da cidade. No ano seguinte, o jornal Correio da Bahia trazia em destaque o "Oitavo concurso de sambão e pagode junino", no já famoso Largo dos Artistas no Engenho Velho de Brotas 4 .

Mas foi a partir do lançamento do disco Swing, do grupo Samba Fama, que parte da comunidade jornalística começou a demonstrar algum interesse pela manifestação em questão. A matéria intitulada "Um disco do Samba Fama", relata as perspectivas de sucesso de um novo seguimento cultural em referência ao que chamam de "novo mercado de disco" baseado no sucesso da gravação de cantores e compositores de blocos afros. O texto, "A novidade agora é o lançamento do disco gravado por grupos de pagode junino, provindo dos bairros populares..." prevê a abertura do mercado musical para o Samba Junino, previsão que, efetivamente, não aconteceu. Alguns poucos anos depois, a indústria fonográfica engessaria a musicalidade

${ }^{3}$ Sobre essa questão ver Oliveira (2001), Döring (2016) e Lima (2016).

${ }^{4} \mathrm{O}$ Largo dos Artistas foi assim batizado pelos integrantes do grupo União por ter sido o lugar de ensaio do Afoxé Badauê, bem como o palco principal do desfile no Samba Junino, atraindo inúmeros artistas famosos, dentre eles Gilberto Gil e Caetano Veloso na década de 80 (MELO, 2017, p. 64). 
mais original/ regional/ natural, crescente nos bairros populares, com a estrutura pop do pagode.

\begin{abstract}
Um disco do Samba Fama. Se der certo, a Bahia começa hoje a investir num novo mercado de discos, depois de lançar com sucesso cantores e compositores de blocos afro. A novidade agora é o lançamento do disco gravado por grupos de pagode junino, provindo dos bairros populares da cidade: Federação, Engenho Velho de Brotas e outros. Quem inaugura o novo "modiscos" (torcemos para que dê certo) é o Samba Fama. O Alto do Gantois, que hoje, às 10 horas, no seu arraial de ensaios (Alto do Gantois), faz o lançamento para a imprensa do LP "Samba Fama, o Swing", com selo da gravadora Continental. A partir das 21h, realiza mais um ensaio, no mesmo local, aberto ao público em geral (A Tarde, 1006 1989).
\end{abstract}

O Jornal A Tarde de 21 de junho de 1990 traz em destaque o samba junino. Nesse artigo o autor reflete sobre questões que vão desde os aspectos políticos a questões estéticas e afirmativas. O ano em que o artigo foi publicado é o período em que a festa começa a aparecer com mais força nas páginas de jornal. O artigo traz, com detalhes, a estrutura do Samba Junino, o nome de alguns grupos e os inúmeros bairros que promoviam festivais e ensaios em Salvador. Com o título "Um São João movido ao som do sambão" a matéria traz, de forma mais detalhada, toda estrutura do Samba Junino, o nome de alguns grupos e os inúmeros bairros que promoviam festivais e ensaios em Salvador. O autor desse artigo, o jornalista Hamilton Vieira ${ }^{5}$, é um escritor negro, ligado ao movimento negro e ao universo cultural afro-baiano, que constrói seus argumentos com base na estrutura social dos bairros periféricos de Salvador, confrontando os elementos da cultura de massa com os da cultura hegemônica. Conforme o autor, o sucesso dos Blocos Afros na década de 70 e 80, como Ilê Aiyê e Olodum, foi a grande inspiração para criação desses grupos de samba. Em sua estrutura, os sambões são administrados de forma semelhante aos Blocos Afros, com "presidente, tesoureiro, ala de canto, etc." Os temas abordados nas letras desses sambões

\footnotetext{
${ }^{5}$ O jornalista Hamilton Vieira faleceu precocemente em 2012, aos 57 anos de idade. Um dos pioneiros na defesa e no reconhecimento da cultura afrodescendente, "Hamilton graduou-se pela Faculdade de Comunicação da Universidade Federal da Bahia (Facom-UFBA), em 1982. Especializou-se em educação e desigualdades raciais pelo Ceafro, instituição do Centro de Estudos Afro-Orientais (Ceao) da Ufba" (UZÊDA, E. 2012, p. 2).
} 
têm como foco principal os símbolos ligados ao São João. Mas, alguns grupos apresentam temas políticos e sociais, quase sempre ligados ao negro, como é o caso do grupo Peão Doido, agora não mais em atividade, e o Grupo Cultural Os Negões. Ambos os grupos são bem representativos em se tratando de criatividade e irreverência no Samba Junino. O Peão Doido, por exemplo, se destacava pela performance. Ele trazia às ruas, pás, picaretas, carrinhos de mão etc., homenageando os trabalhadores do país, mas sempre com uma pitada de malícia. Esse trecho da letra de uma de suas músicas revela o tom crítico com que escreviam:

Subindo a ladeira procurando me armar A polícia me parou, não respeitou o meu crachá Subindo a ladeira procurando me armar A polícia me parou, não respeitou o meu crachá Não, não, não, não, trabalho na obra, mas não sou ladrão Tudo isso acontece porque eu sou peão Trabalho na obra, mas não sou ladrão ${ }^{6}$.

Ou, brincando com as palavras e o jogo fonético, com letras de duplo sentido, revelando machismo/sexismo ainda muito presente na cultura brasileira:

Eh, ah, eh, tu tá danada
eh, ah, eh só querer dançar lambada
Eh, ah, eh, tu ta danada
eh, ah, eh, só querer dançar Lambada
De picareta, enxada, carro de mão
Todo mundo é “cupião” [com o peão]
Todo mundo é “cupião”
De picareta, enxada, carro de mão
Todo mundo é “cupião”
Todo mundo é “cupião”.

O grupo Os Negões, em contrapartida, homenageava os lideres ligados à cultura e ao movimento negro, como o sul-africano Nelson Mandela, o bispo norte-americano Desmond Tutu ou o marinheiro João Cândido etc., todos eles, figuras reconhecidas pela luta em favor dos negros ou qualquer cidadão que se encontrasse em situação de desigualdade. Suas letras de protesto, quando não se referem a figuras de destaque ligadas à causa, buscam

\footnotetext{
${ }^{6}$ Infelizmente ainda não foi possível identificar os autores das duas letras do Peão Doido, aqui citadas, pelo fato de o grupo não existir mais.
}

Pontos de Interrogaçăo, v. 8, n. 2, jul.-dez., p. 179-198, 2018. 
conscientizar a população afrodescendente, como no caso da música "Ser conscientização":

A raça humana consciente tem que se valorizar Não pode os inconscientes Negões, tem que parar pra pensar

Se toda a raça existente na mente plantasse o bem

Não haveria simplesmente um amor sem futuro meu bem Quem vem lá, sou eu, quem vem lá sou eu

Yes, somos Negões, a bola da vez sou eu ${ }^{7}$

Podia haver cobrança de carnês para sair nos grupos e ajudar nas vestimentas e compra de instrumentos. Com o aumento da procura por esses grupos, essa prática se tornou uma eficiente tática para a resistência e sucesso dos sambas. O texto de Hamilton Vieira, (1990, p. 1) também destaca as estruturas dos ensaios que, assim como a maioria dos Blocos Afros, não possuíam/possuem sede, acontecendo nas ruas, "em largos de terminais de transporte coletivo por serem áreas espaçosas, em avenidas de vales, [...], em terrenos baldios, [...]." O sambão também se constituía/constitui numa forma barata de lazer para pessoas de baixa renda, além de favorecer ao comércio local e dar uma renda extra para quem se disponibilizasse a vender bebidas, como cerveja e refrigerante, e tira-gostos, como bata-frita e acarajé etc. Outra questão apresentada pelo mesmo texto ainda é uma realidade muito presente na atualidade. De acordo com o autor, desde 1982 a classe política se utiliza dos sambas para arrebanhar eleitores através dos dirigentes de grupos de samba. Normalmente esses dirigentes têm uma grande penetração nas comunidades, exercendo papel de líderes comunitários. Conforme o texto, a partir de 1982...

[...] um dado novo começa a ser notado nos ensaios destes grupos de samba: a presença de políticos ou de candidatos a um cargo de vereador ou deputado, tanto na área federal como na estadual. [...] em cada local de ensaio podem ser vistas faixas de apoio de um grupo de samba a um político, em geral partidos de direita e centro, [...]. Os postulantes (e mesmo os que já exercem um cargo eletivo) a uma vaga nas várias câmaras fazem contatos com a direção de cada samba, buscando o diretor da entidade (em geral, uma liderança natural do bairro, por ser muito popular), fazendo com que ele utilize seu prestígio junto à comunidade para que este arrebanhe votos para elegê-lo (VIEIRA, 1990, p. 2).

${ }^{7}$ Autores: Da vizinha, Juca Maneiro e Sílvio Almeida. 
É possível perceber esta relação descrita acima ainda hoje, quando políticos se utilizam do Samba Junino no período eleitoral, promovendo eventos, patrocinando a compra de camisas, dando apoio político representativo etc. Em paralelo a essa atividade, e com maior intensidade após o tombamento do samba de roda do Recôncavo como patrimônio cultural da UNESCO em 2005, surgiu um novo e potencial mecanismo ligado às políticas públicas em torno do tombamento do Samba Junino pelo município. Esses fatores mobilizaram a comunidade junina a criarem entidades para atuarem como supostos representantes políticos dos sambas juninos com o objetivo de dar sustentabilidade aos grupos, tanto promovendo ações para a realização de festivais, como no intuito de viabilizar esse tombamento.

Além da Associação Cultural Grupo União fundada em 1978 e responsável pela organização do primeiro Festival de Samba Junino no Engenho Velho de Brotas, conforme relatos dos próprios fundadores Mário e Jorjão Bafafé, outros registros de entidades que atuam como representantes do Samba Junino aparecem a partir de 2000. Há a Federação de Samba Duro Junino do Estado da Bahia - FSDJ em 2000, a Associação do Samba Junino e Samba de Roda do Estado da Bahia em 2005, o Coletivo de Entidades de Samba Junino e Sambas da Bahia - CESBA em 2012, a Associação Cultural Samba Junino do Paletó em 2016, de Feira de Santana, e a Liga do Samba Junino que, pelo que foi presenciado em algumas de suas reuniões, foi criada recentemente, em 2016.

Outro dado importante abordado por Vieira (1990) em seu artigo se refere aos conflitos que aconteciam nesses ensaios públicos. Primeiramente, a relação com a comunidade não tinha um caráter unânime. Muitos se queixavam do som alto, do barulho e da confusão geradas pelas brigas entre grupos rivais. Em alguns desses casos, há o registro de homicídios, porém, sem a conotação atual, em geral ligada ao tráfico de drogas e às facções. Quanto ao barulho, alguns relatos trazidos pelo autor mostram grupos tradicionais que foram forçados a se deslocarem de seus antigos locais de ensaio para outros mais abertos, como no caso do grupo Leva Eu.

Conforme Ninha, a partir da reclamação, os ensaios do Leva Eu passaram a ser feitos no Largo da Capelinha, também no Engenho Velho de Brotas, por ser um local mais amplo, distante das casas dos queixosos. 


\begin{abstract}
Infelizmente, muitas das reclamações dos moradores são procedentes. Em alguns ensaios de samba acontecem muitas brigas, quase sempre entre grupos rivais de rapazes do bairro que se atritam no espaço onde está sendo realizado o sambão. Em alguns casos, ocorrem trocas de tiros e facadas. No mês passado durante o ensaio do Samba do Crioulo Enrolado, do Nordeste de Amaralina ou Vale das Pedrinhas, um rapaz assassinou o outro por causa de um simples pedaço de acarajé. Pasmem! (A TARDE, 21 DE JUN. DE 1990, P. 1).
\end{abstract}

Dentro desse problema, os grupos passaram a fazer um trabalho de conscientização com as comunidades a fim de conter a violência, seja diminuindo o número de filiados ou mesmo utilizando o microfone para acalmar os mais exaltados, comportamento visto ainda hoje em alguns ensaios. É importante ressaltar que ainda não existia o tráfico de drogas, nem facções a ele vinculadas e nem a facilidade de equipamentos de amplificação do som. Dentro desse contexto, vale ressaltar alguns pontos percebidos em pesquisa de campo. Algumas estratégias foram e são adotadas para tentar escapar dos contratempos relacionados ao espaço público, bem como em relação à própria natureza e sobrevivência dos grupos.

Uma delas é a natureza familiar, pois, quase todos os grupos que foram observados fazem seus ensaios na porta da casa do líder, que podia ser o cantor, o diretor ou o presidente, responsável por juntar outras pessoas, tanto plateia quanto os músicos em torno do evento em questão. Essas casas funcionam como estruturas facilitadoras, pois fornecem luz elétrica para iluminar o ambiente e amplificar instrumentos e vozes, bebida e comida para os músicos e demais convidados/público, local para guardar seus instrumentos etc. No caso dos alimentos e bebidas, esses podem ser vendidos para garantir uma renda extra, viabilizar novos ensaios, comprar equipamentos, fornecer o transporte para os músicos que moram distante, o aluguel do sistema de sonorização etc. Os membros moradores dessas residências, bem como a comunidade em geral, também são colaboradores, parte da equipe que prepara a ornamentação e monta o palco, testam os instrumentos e muitas vezes são parte do próprio espetáculo, dançando ou anunciando alguma novidade.

Outro aspecto que parece tão importante para a sobrevivência desses grupos quanto os aparatos fornecidos pelo ambiente familiar é que muitos desses sambas acontecem em locais periféricos, afastados das vias 
principais, em beira de encostas, nos lugares mais humildes, consequência da própria camada social de seus moradores, o que, até certo ponto, tira o foco dos órgãos de fiscalização. Mas isso tudo não funcionaria, sem o engajamento da comunidade que participa da festa, seja simplesmente como audiência ou até mesmo comercializando bebidas e comidas para os frequentadores de tais eventos.

O texto de Vieira (1990) reflete também sobre questões identitárias do povo negro, principalmente jovens, que eram os maiores seguidores desse movimento naquele momento. Para ele, a identidade da juventude negra e mestiça era reforçada com a valorização da estética afro presente nos penteados das meninas. Vieira, em tom crítico, reforça seu compromisso com a causa racial, refletindo sobre o empoderamento da mulher negra, nas "trancinhas e cabelos usados ao natural, sem o recurso do ferro de "fritar cabelo", muito utilizado pela mulher negra na sua busca de se aproximar dos padrões estéticos da branca".

Sobre essa questão é importante destacar o surgimento do Bloco Carnavalesco Ilê Aiyê em 1974 no bairro da Liberdade em Salvador, influenciando o aparecimento de outros grupos e até outros movimentos musicais como o próprio Samba Junino. Sobre esse processo, o texto de Jônatas Conceição ${ }^{8}$ diz:

Mas, na Bahia, o processo de resistência consolidou-se. A maior expressão da resistência político-cultural a tentativa de anulação e apagamento das raízes africanas no nosso meio social, tem como marco a fundação do Bloco Carnavalesco Ilê Aiyê, surgido em 1974, no Curuzu, Liberdade, bairro de maior contingente negro do Estado e quiçá do Brasil (SILVA, 1995, p. 108).

Ideologicamente, as influências e referências mais fecundas do Ilê Aiyê vinham dos movimentos libertários, tanto dos Estados Unidos da América com o Black Power e a luta por direitos civis do negro estadunidense, quanto das lutas de independência dos países africanos, bem como da resistência cultural afro-religiosa no Brasil.

O Ilê Aiyê teve como referências teóricas, na sua idealização, as informações do movimento negro norte-

8 Jônatas Conceição da Silva foi um intelectual negro, militante e coordenador de atividades culturais do bloco afro llê Aiyê, poeta e morador do Engenho Velho de Brotas, falecido em 03 de abril de 2009. 


\begin{abstract}
americano da década de setenta, o "Black Power"; as lutas de independência dos países africanos (principalmente os de língua portuguesa) e a resistência cultural afrobrasileira originária do Candomblé. A partir deste referencial, o Ilê Aiyê desenvolve inúmeras teses sobre a necessidade da solidariedade dos negros entre si, a valorização e o respeito à mulher negra, a valorização das religiões de origem africana, o reforço a auto-estima dos negros, a afirmação de um padrão de beleza negra e, principalmente, o ensino informal da história das civilizações africanas, na medida em que a cada carnaval são homenageadas nações daquele continente (Idem, p. 108).
\end{abstract}

O movimento dos sambas de bairros populares de Salvador surge nesse período, indo na mesma corrente dos Blocos Afros, com os mesmos sentimentos e afinidades, marcando a mudança de comportamento do negro baiano, que passa a adotar uma estética mais africanizada no lugar de uma europeizada, seja nas tranças dos cabelos ou nas roupas e adereços. Isso revela uma ampla mudança ideológica representada pelo Ilê Aiyê, inspirando a população que transita nesses espaços a adotarem também um novo visual.

Em outro artigo publicado no jornal A Tarde em junho de 1991, escrito pelo jornalista Hamilton Vieira, percebe-se o envolvimento dos bairros populares para a realização de concursos de samba, alguns inclusive, com premiação em dinheiro patrocinados por políticos.

O II Concurso de Samba do Bairro do Garcia, por exemplo, que aconteceu domingo e segunda-feira, no Largo da Fazenda Garcia, teve o apoio de um postulante a Câmara Municipal, que, entre outros prêmios, distribuiu Cr\$30 mil, para o samba classificado em primeiro lugar, $\mathrm{Cr} \$ 15$ mil, para o segundo e Cr\$10 mil, para o terceiro (A TARDE - CADERNO 2, 26 JUN. 1991, P. 1).

Analisando a repercussão da manifestação em questão, o artigo de Viera traz o nome dos grupos mais populares de Salvador, dentre eles, o Leva Eu e o Jaké, ambos do Engenho Velho de Brotas. Comparando os grupos juninos aos Blocos Afros e ressaltando a presença de pessoas negras na sua formação, Hamilton Vieira deixa claro o seu compromisso com a cultura negra presente nesses bairros.

Como os blocos afros, há grupos que conseguem ter um maior número de participantes ou simpatizantes. Os mais populares são Samba Scorpius (Engenho Velho da Federação), Unidos do Capim (Vale das Pedrinhas), Pião 
Doido (Garibaldi), Fama (Alto do Gantois), Leva Eu, Jaké (Engenho Velho de Brotas), Samba do Morro (Alto da Bola, Federação) e, entre outros, Fogueirão (Vasco da Gama) (Idem, 26 jun. 1991, p. 1).

No que se refere à parte musical, o texto reforça a variedade rítmica do conjunto percussivo de cada grupo, consequência da busca por uma identidade. Vale ressaltar, que a participação e presença de músicos prestigiados nos ensaios de vários grupos sempre foi constante. Nomes como o do saxofonista Augusto Conceição, os percussionistas Gabi Guedes e Carlinhos Brown, ou até mesmo músicos de outros contextos como Armando de Melo Bastos, conhecido como Bastola do grupo Tríade e da Orquestra Sinfônica da Bahia, eram frequentadores dos ensaios do grupo Leva Eu, no Engenho Velho de Brotas. Em seu depoimento para o jornal, Bastola ressalta a organização dos sambas, bem como a criatividade de cada grupo e o importante papel de mantenedores da cultura joanina.

\begin{abstract}
Bastola, além de ressaltar o grande nível de organização dos sambões juninos, disse ficar muito encantado com a variedade de toques imprimidos por cada grupo. "Cada grupo tem a sua levada, o seu ritmo característico, que é algo interessante musicalmente". O músico lembrou ainda que estes grupos de samba são importantes por contribuírem para a continuação do São João em Salvador. "Os sambões são uma ótima opção para juventude dos bairros populares, que muitas vezes não tem condições financeiras de viajar para o interior" (IDEM, 26 JUN. 1991, p. 1).
\end{abstract}

Ainda sobre a presença de músicos importantes na cena musical baiana, e o contexto do Samba Junino, o baterista Ivan Huol, do Grupo Garagem, em seu depoimento para a pesquisa, contou como foi sua experiência junto ao grupo Leva $\mathrm{Eu}$, participando dos ensaios de samba durante oito anos no Engenho Velho de Brotas, bem como, acompanhando o grupo como integrante. Em 1984, por intermédio do músico Tony Mola, ele passou a frequentar os ensaios do grupo, talvez no intuito de navegar por outros contextos musicais. Durante esse período, foi construída uma amizade musical para além do samba, especialmente com um dos integrantes do Leva Eu, o músico percussionista Zé Carlos, gerando assim, uma parceria musical com o Jazz. Sua participação como músico do samba, lhe levou aos festivais anuais no São João, visitando os bairros vizinhos e suburbanos, atraindo 
músicos de outros contextos, tal qual o próprio Bastola citado pelo jornal A Tarde.

Dentre os muitos aspectos abordados por ele estão: a qualidade musical dos instrumentistas, uma prática herdada, inconteste; a técnica de canto, cuja rítmica é bastante específica, sem os vibratos e com muitos glissandos; a complexidade rítmica da percussão. Questionando a influência da indústria musical na música proveniente de bairros populares, ele indaga sobre a visão planificada dessa indústria e a tentativa de "normatização" de suas características, ajustadas ao que se tem como "certo", numa concepção europeizada da música (utilização de metrônomo, entonação dentro do campo harmônico etc.), e o processo de extrativismo midiático, certamente baseado no consumo. Esse comportamento da mídia, de certo, tende a excluir a população negra e/ou mestiça da participação e penetração em espaços de projeção social, como os dos meios de comunicação, dificultando a inserção desses artistas no mercado cultural.

Apesar de toda dificuldade de projeção midiática e exclusão dos processos geradores de riqueza, a resistência do negro baiano se revela ainda mais forte. A matéria do jornal A Tarde de maio de 1993, com texto de Hamilton Vieira, publicada no caderno Lazer e Informação, reafirma essa premissa. Nela, a cultura negra apresenta seu poder de transformação na necessidade de criação e reconhecimento pelo seu povo, uma força que revela, em si mesma, um enfrentamento político-racial dentro de um universo cultural de origem europeia. Em "Sambão Junino: africanizando o São João lusitano", o autor mostra a força da cultura africana em Salvador e o seu poder de transformação, adicionando o elemento da cultura afrobrasileira, modificando a tradição de origem lusitana. Conforme o texto:

A força da cultura africana em Salvador é tão forte que altera tudo: agora é a vez do São João, de tradição lusitana, que os "Sambões juninos" ou "Samba-são-joão" transformam em palco para samba duro, levada e reggae, criando uma coisa nova, que termina sempre em arrastão, com a população dos bairros, seguindo atrás dos ritmistas (A TARDE, CAD. L\&I, 09 DE MAIO 1993, P. 1).

Já o texto principal, na página 10, traz detalhes sobre a configuração rítmica, estética, influências ligadas diretamente ao candomblé, num paralelo entre a cultura do típico São João com os costumes afro-baianos. 
A maneira como os grupos de "sambão junino" de Salvador festejam o São João e São Pedro acaba dando uma característica afro-baiana a estas comemorações lusoreligiosas, trazidas pelos padres e portugueses que vieram colonizar o Brasil. Tradicionalmente, o que caracterizava as festas de junho, eram as quadrilhas, atualmente mantidas em Salvador apenas nas festas escolares [...] (A TARDE, 9 DE MAIO 1993, P. 10).

Mas, o que teriam em comum, o "sambão" presente no Samba Junino e o forró do São João? Refletindo sobre esses dois universos, aparentemente tão díspares, encontram-se alguns elementos que, de certa forma, fazem a ligação entre os diferentes contextos. Grande parte do repertório do Samba Junino, por exemplo, é composto de músicas de samba de roda, e essas, por sua vez, trazem temas que se referem ao universo rural em suas letras. Dessa forma, ele estaria ligado ao São João, cuja presença é infinitamente mais intensa no interior do estado. Os instrumentos musicais tradicionais na cultura joanina, como zabumba, triângulo e sanfona, também poderiam ser associados ao universo rural com a viola e o sertão. Como nesse tema:

\author{
Pisa na galha do boi, \\ Segura na galha do boi, oh mulher \\ Segura na galha do boi, oh mulher \\ Segura na galha do boi, oh mulher \\ Ou então: \\ Vou embora pro sertão, oh viola, meu bem viola \\ Eu aqui não me dou bem, oh viola, meu bem viola \\ Sou empregado da Leste, sou maquinista do trem \\ Vou me embora pro sertão, eu aqui não me dou bem \\ Oh viola meu bem viola
}

Como visto, os signos de uma africanidade latente na cidade de Salvador confronta seus elementos à cultura luso-brasileira, simbolicamente reforçando os elementos culturais do povo negro, e, de certa forma, satisfazendo um desejo requerido pelos mesmos, de maneira ressignificada, utilizando os símbolos próprios de sua cultura, mas também se ligando ao São João através de algumas características semelhantes e/ou compartilhadas.

Como apontado anteriormente, a influência dos Blocos Afros e o ideal afro-libertário do Movimento Negro Unificado foram de fundamental importância para a deflagração desse contexto. Destaca-se aí a presença do jornalista Hamilton Vieira, tantas vezes citado nesse trabalho, como uma das vozes em defesa e promoção da cultura negra em Salvador, assumindo uma 
postura militante dentro de um veículo de comunicação como o jornal. Numa matéria anterior, também do jornal A Tarde, publicada em 23 de junho 1989 no Caderno 2, Hamilton Vieira reforça a influência e importância política do movimento negro frente a cultura soteropolitana, ressaltando o ativismo do bloco afro “Os Negões" e sua luta pela difusão dessa mesma cultura.

Na Festa de São João deste ano, amanhã, os integrantes do pagode de Os Negões sairão acompanhados pela banda Gangazumba do bloco afro Muzenza, a partir das 16 horas, do Terreiro de Jesus. O destino será vários bairros da cidade, com passagem pelos bairros do Engenho Velho da Federação e de Brotas, onde estão praticamente todos os grupos de samba da cidade, locais dos mais animados durante os festejos juninos (JORNAL A TARDE, 23 DE JUNHO DE 1989, P. 1).

Nesse contexto vale ressaltar, que o universo afrocêntrico da Soul Music negra norte-americana e os movimentos contra-hegemônicos da época foram importantes para a valorização da cultura negra entre alguns dos principais articuladores culturais do bairro como os já relatados anteriormente, Mário e Jorge Bafafé. Dentro desse universo midiático é importante destacar, além do jornalista Hamilton Vieira, a figura do poeta, professor e radialista Jônathas Conceição como outro importante propagador da cultura afro baiana, não só como escritor, engajado com a causa antirracista, mas também como apresentador da Rádio Educadora da Bahia no início dos anos 80. Nesse período, apresentou o programa chamado "A negritude está presente", trazendo pessoas ligadas ao movimento negro, dentre elas integrantes de Blocos Afros. O dançarino e coreógrafo Negrizu, que também foi um dos entrevistados num desses programas, relata que:

Uma das rádios é essa, a Rádio Educadora, tá. E o programa era “a Negritude está presente”. Trouxe muita gente de Blocos Afros e tal, e eu tava... me destacava, meio a essa galera. Aí, por causa da dança e tal, e como era uma coisa nova, o negrinho dançando... Tem uma matéria: "Negrizu: o neguinho que dança barbaridade". Eu fui falar sobre isso. Me parece que é em 1980. Eu acho que eu ia ser o "moço lindo", [ou] eu ia concorrer! Eu fui o moço lindo do Badauê. Se foi o moço lindo do Badauê, já foi em 81 [1981]. Que eu me lembro, é mais ou menos isso daí, 13 dos 02 de 1981. Tô vendo cravado no Troféu. 13 dos 02 (NEGRIZU, apud MELO, 2017, p. 51). 


\section{Processo de registro especial do patrimônio cultural e seus desdobramentos}

No dia 16 de junho de 2016, aconteceu no Parque Solar Boa Vista, bairro do Engenho Velho de Brotas, a cerimônia de notificação pública para o processo de registro especial do samba junino, processo esse, requisitado pela Associação Só Samba de Roda e o Sindicato dos Músicos da Bahia. O evento foi inserido no projeto Boca de Brasa, promovido pela prefeitura e a Fundação Gregório de Mattos, e contou com a participação de grupos de samba junino, representantes de associações e artistas convidados. O resultado do pedido havia saído no Diário Oficial do Município em 13 de junho do mesmo ano, assim dando início ao processo de levantamento de dados para elaboração do dossiê técnico. Este incluiu um estudo etnomusicológico e etnohistórico, amarrados à oralidade e todas as fontes jornalísticas possíveis, um mapeamento dos principais redutos do samba junino, o universo imagético e sonoro, bem como, indicativos preliminares para produção de um plano de salvaguarda. ${ }^{9}$ É importante ressaltar que o dossiê ficou disponível por meios digitais no site da instituição promotora (Fundação Gregório de Mattos) para que a comunidade de integrantes dos grupos de samba junino pudesse tomar conhecimento, ler e opinar, antes do material ser encaminhado para a análise e aprovação final.

Até este momento da consulta pública, já tinham ocorrido várias discussões no âmbito dos grupos em relação a importância, ou não, do possível registro como patrimônio cultural, pois estava sendo colocado em xeque que o samba junino estava redefinindo sua relação com o poder público, algo até então mais latente. Como colocado anteriormente, vários grupos tiveram relação de proximidade com políticos por causa de iniciativas de ambos os lados, assim permitindo apoios mútuos, mas sempre ligados a interesses de um grupo de samba específico que, em geral, individualmente buscava seus apoios, no máximo para a realização de um festival, que envolvia vários grupos.

O processo de registro criou uma situação nova que colocou os grupos em uma situação de horizontalidade e concorrência perante o poder

\footnotetext{
${ }^{9}$ A elaboração do estudo etnomusicológico e do parecer final foram solicitados só em 2017 aos autores deste texto e, após concluídos, foram integrados ao dossiê (BARBOSA, 2017).
} 
público entre si, antes não experimentada, já que cada grupo atuava principalmente em seu bairro. Esta mudança ocorreu a partir do lançamento de um edital para comemorar o primeiro ano do samba junino como patrimônio cultural da cidade. O edital Prêmio Samba Junino foi lançado em 2018 por iniciativa da Fundação Gregório de Mattos, como primeira iniciativa para a salvaguarda do samba junino. O edital previa a contemplação de 06 projetos no valor de $\mathrm{R} \$ 30.000,00$ destinados à salvaguarda do samba junino, cujas propostas pudessem incentivar o fortalecimento e a manutenção do Samba Junino na capital. Ações como, a realização de ensaios, festivais, concursos, apresentações e "arrastões", poderiam fazer parte dos objetivos dos produtores, com realização prevista para o período junino. Este edital gerou imediatamente discussões acirradas entre os grupos, pois havia muito mais grupos do que prêmios previstos. Indiretamente o edital priorizava a participação de associações, provavelmente no intuito de agregar o maior número de grupos de samba. Mas, nem todos os grupos estão filiados a associações e estas, historicamente, mantinham relação de desconfiança e até conflito entre si e os sambistas, principalmente quando havia aporte financeiro envolvido. Obviamente, os projetos a serem aprovados pelo edital não contemplariam grande parte dos grupos, que por sua vez, não eram tão organizados politicamente nem possuíam/possuem registro como grupo cultural com CNPJ ou outros documentos, fato que os deixaria de fora desse processo. Tudo isso gerou discussão durante o processo de inscrição e ainda mais desconfiança em relação aos contemplados, aumentando os conflitos entre os grupos. Para complicar ainda mais a situação, durante esse processo, grupos de samba com estilo semelhante aos do Rio de Janeiro, que antes rejeitavam ou não compartilhavam dos mesmos interesses do samba junino, apareceram como grupos de samba junino ou ligados ao mesmo, tentando "abocanhar uma fatia desse bolo", o que distorceu ainda mais o processo de construção de identidade do samba junino.

Assim, em contraposição ao objetivo principal e coletivo proposto pela salvaguarda, o reconhecimento e fortalecimento da tradição, surgiram questões que podem gerar alguns desgastes. O samba junino, manifestação de caráter familiar e, quase sempre sem fins lucrativos, depara-se com uma nova forma de injeção de dinheiro, que já existia antes, porém de forma modesta, com base na permuta entre políticos e os sambas. Mas, agora parece gerar interesses contrários entre os grupos, até mesmo entre os associados, o que 
levou a uma situação que só no decorrer do tempo, com uma participação maciça de representantes dos grupos, pode ser melhorada para atender ao que foi proposto através da proposta de registro como patrimônio cultural. Questões como estas também foram apontadas em outros estudos sobre o impacto de políticas de patrimônio cultural, como p.ex. em Campos (2013) e Guillen (2013, p. 218) e certamente precisam de muita discussão, também no âmbito do samba junino, que segue os passos já experimentados do seu "primo", o samba de roda do Recôncavo baiano, já inventariado (SANDRONI, 2005). Desde então o samba de roda tem tomado posições de protagonismo a partir da atuação dos grupos vinculados à casa do Samba em Santo Amaro, mesmo que o processo não tenha sido realizado sem discussões e conflitos internos.

\section{Conclusão}

A história do samba junino é contada com orgulho pelos seus criadores. Um passado que persiste em não sair da memória de homens e mulheres que contribuíram para o fortalecimento e sobrevivência desse movimento, agora, patrimônio cultural da cidade $^{10}$. Com esse dado novo acrescentado à sua história outros desafios surgem para serem superados. No âmbito político, por exemplo, surge a necessidade de definição e execução de um plano de salvaguarda que inclua um estudo mais profundo sobre especificidades do samba junino, no tocante à indumentária, à dança, à música, ao ritmo do samba duro e oficinas de criação de instrumentos. É indispensável pensar na definição de um calendário oficial para o samba junino, bem como equipar os locais de apresentações e festivais com mecanismos básicos para a realização de eventos em locais públicos. Outra ação que parece importante é a definição de um possível local como sede para o samba junino, onde possam ser discutidas questões relacionadas à manifestação, seja também local para apresentações, com a criação de um acervo com vídeos, fotos, textos, registros fonográficos etc. Nota-se, então, a necessidade de dar seguimento à "brincadeira", levando às novas gerações,

\footnotetext{
${ }^{10}$ Apesar da participação de mulheres no samba junino, não apenas como dançarinas, mas também como promotoras e diretoras de alguns grupos, os sambas juninos são compostos, em grande maioria, por homens, quase todos negros e moradores de comunidades de baixa renda, onde a maior atividade cultural é o samba.
} 
fato que começa a ser pensado e até realizado por algumas entidades, mesmo que de maneira ainda pouco expressiva.

Em relação à preservação e memória são poucos os registros fonográficos do samba junino. Os dois primeiros, importantes para o processo de consolidação do samba junino como manifestação cultural e histórica, foram produzidos em 1989: o disco "Swing" do Samba Fama, reverenciado até os dias atuais, cantado por muitos, e a coletânea "Os melhores sambas de São João da Bahia”. O primeiro, o disco "Swing”, traz um repertório intimamente ligado ao candomblé, com predominância do samba duro, além de um poutpourri com sambas de caboclo. ${ }^{11} \mathrm{O}$ segundo disco é mais diversificado, com grupos de diversas regiões de Salvador. Ele traz um repertório variado, que alude para a diversidade cultural da cidade e traz músicas que transitam entre o samba reggae e o samba duro ${ }^{12}$. Após o ápice das gravações de grupos musicais com percussão em Salvador, Ilê Aiyê, Olodum, além dos próprios grupos de samba duro, a indústria fonográfica engessaria a musicalidade mais regional, crescente nos bairros populares, com a estrutura pop do pagode. No caso do samba junino, sua estrutura não prevê, necessariamente, uma dinâmica semelhante às músicas gravadas em estúdio e/ou tocadas nas rádios. O canto sem vibrato, executado de forma reta, com uma articulação mais percussiva, e a variação constante de andamento de forma intencional. A criação e recriação dos arranjos em performances ao vivo, o uso de um repertório, muitas vezes, "tirados de cabeça", memorizados e improvisados com o uso de elementos do cotidiano, com liberdade para transformar um momento da performance em um novo tema. Algumas dessas características destoam do ambiente métrico das gravações em estúdio, o que, talvez, tenha transformado essa estrutura, mais aberta e livre de convenções, no que veio a se chamar de pagode.

Por essas e outras questões, acredita-se que o sucesso de grupos de pagode aos poucos enfraqueceu o movimento de rua do samba junino. Muitos de seus participantes, atraídos pela possibilidade de conseguirem fama,

\footnotetext{
${ }_{11}$ Destaque para as músicas "A Rolinha" de (Robson de Jesus) e "Tereza na fogueira" de (Marquinhos Fama, Augusto Conceição e Tinho Fama).

12 Há grupos como Os Negões, com o seu samba reggae meio funk na música "Passos" do autor do autor Dude Santiago, e o Samba Scorpions, do cantor Tatau, ex-Araketu, com uma levada de samba duro e o uso de instrumentos de harmonia. Destaque para a música que abre o disco "Quero ser seu namorado", de autoria de Tatau, música que alcançou as rádios soteropolitanas.
} 
prestígio e o sucesso desses grupos, se enveredaram pelo pagode, e os jovens dos bairros populares não mais se interessaram em correr às ruas do bairro fazendo samba junino. Poucos grupos resistiram desfilando pelas ruas de poucos bairros e sem a mesma força de tempos atrás. Mas como Campos aborda na sua análise das políticas públicas referentes ao samba de roda (CAMPOS, 2013, p. 53), é possível criar diálogos entre a tradição e novos formatos de apresentação e representação, sem oposição antagônica, algo que se espera para o contexto do samba junino também.

Esse novo contexto do samba junino, com o reconhecimento público de sua contribuição para a cultura afro-baiana, introduz novo ânimo. Uma manifestação de enorme riqueza e criatividade, moldada pela diversidade inerente ao seu tempo, de caráter participativo e alegre como seu povo. Com mais de quarenta anos de resistência e uma invisibilidade histórica, certamente ligada a sua origem subalterna, tem finalmente o seu valor reconhecido como patrimônio cultural da cidade de Salvador, mas requer a contínua presença de representantes dos grupos na discussão das políticas que possam se destinar aos grupos e associações, tanto para registrar e documentar as trajetórias de grupos, quanto continuar na busca de novos caminhos possíveis, dentro do cenários de editais e outros mecanismos de apoios culturais.

\section{Referências}

BARBOSA, Magnair. (Org.) Samba junino: processo de registro especial do patrimônio cultural. Salvador: Fundação Gregório de Mattos, 2017. 228 f. il.

CAMPOS, Lucia. Sobre a salvaguarda de uma prática musical: uma etnografia do samba de roda na World Music EXPO. In: SANDRONI, Carlos; SALLES, Sandro Guimarães de. Patrimônio Cultural em discussão: novos desafios teóricos metodológicos. Recife: Editora Universitária UFPE, 2013, p. 43-55.

DÖRING, Katharina. Cantador de Chula: O samba antigo do Recôncavo. 1. ed. Salvador: Editora Pinaúna, 2016. 256 p.

GUILLEN, Isabel Cristina Martins. O historiador e as políticas públicas sobre patrimônio cultural. In: SANDRONI, Carlos; SALLES, Sandro Guimarães de. Patrimônio Cultural em discussão: novos desafios teóricos metodológicos. Recife: Editora Universitária UFPE, 2013, p. 212-231.

LIMA, Arivaldo. Uma crítica cultural sobre o pagode baiano: música que se ouve, se dança e se observa. Salvador: Editora Pinaúna, 2016. 128 p. 
LITERAFRO: O portal da literatura brasileira. Disponível em: http://www.letras.ufmg.br/literafro/autores/291-jonatas-conceicao. Acesso em: 10 dez. 2018.

LÜHNING, Ângela; MELO, Gustavo J. J. de O samba junino em Salvador: estudo etnomusicológico. In: BARBOSA, Magnair. (Org.) Samba junino: processo de registro especial do patrimônio cultural. Salvador: Fundação Gregório de Mattos, 2017, p.70 - 118.

MELO, Gustavo, J. J. de. Samba Junino: o samba duro e o São João de Salvador. 154 f. il. 2017. Dissertação (Mestrado) - Escola de Música, Universidade Federal da Bahia, Salvador, 2017.

SANDRONI, Carlos. (Coord.). Samba de Roda do Recôncavo Baiano. Brasília: IPHAN, 2005.

SILVA, J. C. O querer é o eterno poder: História e resistência no bloco afro. Afro-Asia-UFBA, Salvador, v. 16, p. 107-115, 1995.

SOUZA, F. S. Jônatas Conceição, um poeta afro-brasileiro. Letras de Hoje, Porto Alegre, v. 46, n. 4, p. 40-44, out./dez. 2011. Disponível em: file:///C:/Users/DELL/Downloads/10204- 36991-1-PB.pdf. Acesso em: 22 jun. 2017.

UZÊDA, E. Morre, aos 57 anos, o jornalista Hamilton Vieira. Jornal A Tarde, Bahia, dez. de 2012. Disponível em: http://atarde.uol.com.br/bahia/salvador/noticias/1472905-morre-aos- $\quad$ 57anos-o-jornalista-hamilton-vieira. Acesso em: 30 de jun. 2017.

VIEIRA, Hamilton. Negros relembram João Cândido/Roteiro do pagode. Jornal A Tarde, Salvador, 23 jun. 1989. Caderno 2, p. 1

VIEIRA, Hamilton. Um São João movido ao som do sambão. Jornal A Tarde, Salvador, 21 jun. 1990. Caderno 2.

VIEIRA, Hamilton. Sambão junino: africanizando o São João lusitano. Jornal $A$ Tarde, Salvador, 09 mai. 1993. L\&I, p.10

Recebido em: 31/10/2018

Aprovado em: 04/12/2018 